\title{
Relationship between Students' Attitudes Toward Their University and Academic Burnout: Examining the Mediating Role of Academic Procrastination
}

\author{
Taraneh Enayati, ${ }^{1,}$ and Fatemeh Rastegar Tabar ${ }^{2}$ \\ ${ }^{1}$ PhD of Educational Management, Associate Professor, Department of Educational Sciences, Sari Branch, Islamic Azad University, Sari, Mazandaran, IR Iran \\ ${ }^{2}$ M.A. of Educational Management, Department of Educational Sciences, Sari Branch, Islamic Azad University, Sari, Mazandaran, IR Iran \\ "Corresponding author: Taraneh Enayati, Department of Educational Sciences, Sari Branch, Islamic Azad University, Sari, Mazandaran, IR Iran. Tel: +98-1134445461, Fax: \\ +98-1133033851, E-mail: tenayati@yahoo.com
}

Received 2017 May 09; Accepted 2017 May 19.

\begin{abstract}
Background and Objectives: Thoughts and behaviors of university students are influenced by their expectations from the university and their perception of the university environment. If these expectations are not met, they may even consider quitting the university. The current study evaluated the relationship between students' attitude toward the university and academic burnout, and examined the mediating role of academic procrastination.

Methods: The current cross sectional study was conducted on 384 students of Mazandaran University of Medical Sciences and Islamic Azad University, Sari Branch, who were selected using stratified random sampling based on the location of the university. The sample size was determined based on the specific population of the community. Data were collected using a standardized questionnaire on students' attitude toward the university developed by Weinstein et al., which assessed their perception, expectations, emotions, and knowledge (PEEK). Additionally, the academic procrastination scale developed by Sevari, and the academic burnout questionnaire by Breso et al. were used. Data were analyzed using the independent $t$ test, correlation coefficient test, and the path analysis method using repeated-measure regression models.

Results: A significant correlation was observed between the students' attitudes toward the university and their academic procrastination $(r=0.298)$ and academic burnout $(r=0.491)$. There was significant relationship between the students' attitudes toward the university and their academic burnout mediated by two dimensions of procrastination: intentional and mental and physical fatigue (P value < 0.05). Further, a comparison of the studied variables between the students of Mazandaran University of Medical Sciences and Islamic Azad University, Sari Branch, indicated significant differences in the students' academic and personal aspects, in their attitude toward the university, and in their academic failure component as a factor of academic burnout; but no significant difference was observed regarding the other studied variables.

Conclusions: To promote the academic performance and psychological well-being of students, more attention should be paid to improving their attitudes toward the university in order to reduce and avoid academic procrastination and burnout.
\end{abstract}

Keywords: Students' Attitudes toward the University, Academic Procrastination, Academic Burnout, Path Analysis

\section{Background}

Mental health leads to physical health and happiness, as it is one of the evolutionary and developmental factors for human beings. Students' mental health is of great importance. Although students are the outstanding people of the community, several studies have reported that they may develop different emotional complications and disorders (1). Nowadays, students in Asian countries have been found to experience high degrees of academic stress due to higher levels of familial and cultural expectations; as academic achievement is a way to achieve premier carrier opportunities (2). Such pressures may cause physiological symptoms associated with emotional exhaustion, which in in turn may cause academic burnout $(3,4)$.
Freudenberger et al. are among the pioneering researchers who investigated academic burnout, and they proposed that academic burnout with particular signs mostly occurs in perfectionists owing to the inability to meet the high standards that they expect, which may exacerbate their distress and burnout (5). Academic burnout has a significant relationship with maladaptive perfectionism (6), and perceived stress is considered to be the strongest predictor of students' academic burnout $(7,8)$.

Different factors such as social protection failure, excessive stress, and personal characteristics may result in academic burnout. Results of previous studies indicate that students who experience excessive degrees of stress, which leads to academic burnout, may exhibit alarming physical, emotional, and mental symptoms (9). 
Academic burnout refers to the feeling exhaustion that occurs due to high expectations regarding studying (exhaustion), a pessimistic attitude toward one's university (pessimism), and a feeling of inadequacy as a student (low effectiveness) (4). In fact, university students may experience burnout because the present educational environment requires them to invest more efforts, and the supportive mechanisms do not facilitate the development of strategies to cope with the problems (10).

The burnout mostly occurs when there is an incompatibility between the nature of a task and the nature of the person attempting it. People with academic burnout usually develop symptoms such as academic disinterest, inability to attend classes continuously, lack of participation in classroom activities, continuous absence, feelings of inequality, and feeling of meaninglessness in learning the lessons (11). Results of a study showed a significant relationship between academic self-concept, academic burnout and its subscales (exhaustion, disinterest, and academic failure), and academic performance (12).

Academic procrastination is another factor involved in the development of academic burnout. Different studies have reported that the academic performance and educational activities of university students are not optimal, and these aspects may be attributed to academic procrastination. Academic procrastination may lead to negative effects on the education, and consequently, the personal life of students. Academic procrastination refers to an illogical tendency toward postponing the initiation or completion of a task. Hence, learners may tend to complete their academic tasks in a given or expected time, but they may be unable to keep themselves motivated during such tasks. Consequently, students are unable to complete tasks effectively, owing to involvement in unnecessary works and fleeting pleasures (13). The procrastination mostly results in stress, distress, and continuous failure. Although procrastination is not always problematic, it may have undesirable and irreparable consequences through the inhibition of progress on and prevention from achieving task goals (14).

Nowadays, procrastination is a common psychological problem among students (15), which can disrupt their academic performance and progress (16). Results of a study indicated that about $24 \%$ and $37 \%$ of the students participating in their study developed high and very high degrees of procrastination, respectively; and that there was a significant relationship between anxiety and depression, and procrastination (17). According to previous studies, about $80 \%$ to $95 \%$ of students deal with procrastination in some form or the other (18), about $75 \%$ believe that they are procrastinators, and 50\% repeatedly exhibited academic procrastination (19). Results of a study by Sepehrian showed that anxiety was a significant predictor of academic procrastination (13). Tamadoni et al. reported a significant negative relationship between general self-efficacy, and academic procrastination and progress (20).

The students are the greatest human capital in every community as they can promote the progress and development of the society by combining the spirit of youth with learned knowledge and skills. Nowadays, learners are exposed to different challenges in the educational environment that affect their achievement of academic goals. If such challenges are neglected, the resultant irrecoverable consequences may affect their attitude, academic performance, and psychological well-being (6). Students' beliefs and attitudes toward their future experiences in the university may affect their thoughts and performances during university education. Many talented and capable students drop out of the university during the 1st academic year due to personal or social problems, and/or educational expectations that cannot be fulfilled (21). Hence, thoughts and attitudes toward the environment of the university can be considered as factors associated with academic procrastination and burnout; factors such as attitudes toward the situation in the university, academic performance, considering oneself deserving of a fellowship, and being able to handle academic tasks solely can induce academic burnout. The study by Naami showed significant relationships between the quality of learning experiences in different areas (e.g., references, contents, flexible learning, and the teacher-student relationship) and academic burnout aspects (academic exhaustion, disinterest, and academic failure) (11).

As the pessimistic attitude toward university is one of the factors attributed to educational burnout among students (4) and it governs their future attitudes, performance, and behaviors (22), special attention should be paid to students' attitude toward their university as a factor affecting academic procrastination and burnout. Results of a study showed a negative relationship between the atmosphere of a university and positive motivation by teachers, and educational burnout (11).

According to Weinstein et al., perceptions, expectations, beliefs, and attitudes of students toward their university is divided into academic, personal, and social aspects. The academic aspect refers to students' expectations about difficulties, solutions, nature of learning, roles and responsibilities of teachers, and nature of the academic curriculum. The personal aspect refers to the self-perception of students regarding emotional reactions to the university, their perception about their academic achievements and/or academic activities, the correspondence between academic activities and future goals, and the level of academic responsibilities. The social aspect 
refers to the relationships among social pressures in the university; interaction with teachers; structure and demographic characteristics of the university; the relationship among families, students, and friends; and participation in student and social activities. Perceptions, expectations, emotions, and information regarding the university are potential instruments to evaluate students' ideas, attitudes, beliefs, and expectations regarding their perception about the university; on the other hand, students' expectations regarding their future experiences in the university significantly affect their thoughts, academic performance, and satisfaction (21).

To the authors' best knowledge, no study has investigated the relationship of students' attitude toward their university and academic procrastination with the level of academic burnout they exhibit. Therefore, the current study aimed to evaluate the relationship between students' attitude toward their university and academic burnout, and to explore the mediating role of academic procrastination in this relationship.

\section{Methods}

The current cross sectional study was conducted on the students of Mazandaran University of Medical Sciences and Islamic Azad University, Sari Branch. The universities that were selected were required to include at least 1 medical field, and accordingly the students of the 2 mentioned universities were selected during the academic year of $2014-15$.

The sample size was determined based on the population of the community and the following formula was used (Equation 1).

$$
\mathrm{N}=\mathrm{Z}^{2} \mathrm{NP}(1-\mathrm{P}) / \mathrm{d}^{2}(\mathrm{~N}-1)+\mathrm{Z} 2 \mathrm{P}(1-\mathrm{P})
$$

According to the abovementioned formula, the sample size was estimated at 384; subjects were selected by stratified random sampling based on the university, and an equal sample was selected from both universities. The authors visited the universities, selected the subjects randomly out of the students present, and distributed the questionnaires among the subjects after they had signed the informed consent form without any obligation. The subjects participated in the study voluntarily, and they were assured about the confidentiality of the data.

Out of the 384 subjects enrolled in the current study, 192 were from Mazandaran University of Medical Sciences, and 192 from Islamic Azad University, Sari Branch; 241 were female and 135 male.

Data were collected using the questionnaire developed by Weinstein et al. (21) on the students' attitude toward their university, including perception, expectations, emotions, and knowledge (PEEK). Additionally, the academic procrastination scale developed by Sevari (23), and the academic burnout questionnaire by Breso et al. (24) were used.

The PEEK questionnaire: This instrument was developed in the University of Texas in Austin, during the implementation of a project on cognitive learning strategies by Weinstein et al. (21). The early exploratory information required to develop the questionnaire was collected in 3 to 4 years, from 3000 students and faculty members. Information on possible personal, social, and academic differences was evaluated in different university environments and students, and finally 300 items were extracted. It took more than 2 years to evaluate and integrate the items, and the questionnaire was finally changed into a short form that was easy to implement. The questionnaire includes 30 items on the aspects of academic, personal, and social attitudes (10 items on each aspect), scored using a 5-point Likert scale (ranging from I am not interested at all $=1$ to I am very interested $=5$ ). Although the development procedure of the questionnaire approves its validity and reliability, as it was translated from English to Persian by the present researchers, its validity was re-evaluated and approved by the experts. It reliability was determined based on a Cronbach's alpha coefficient of 0.85 .

The academic procrastination scale: Sevari developed this scale and it includes 12 items on intentional procrastination ( 5 items), procrastination due to physical and mental fatigue (4 items), and procrastination due to disorganization (3 items). It is scored on a 5-point Likert scale (from 0 $=$ never to 4 =always). The validity of the scale was assessed by its correlation with Tuckman procrastination scale as 0.35 , which indicated the good validity. Sevari approved the reliability of the scale based on the Cronbach's alpha coefficient of $0.85,0.77,0.65$, and 0.70 for the total scale and the 1st, 2nd, and 3rd factors, respectively (23).

The academic burnout questionnaire by Breso et al.: This questionnaire includes 15 items on academic exhaustion (5 items), academic disinterest ( 4 items), and academic failure (6 items) scored using a 5-point Likert scale (from $1=$ completely disagree to $5=$ completely agree) (24). Naami reported the reliability of the academic burnout questionnaire for the aspects of academic exhaustion, academic disinterest, and academic failure as $0.79,0.82$, and 0.75 , respectively (11). In the current study, the Cronbach's alpha coefficient was 0.80 .

Data were analyzed using the descriptive statistics (such as frequency, percentage, mean, and standard deviation), inferential statistics (such as the independent $t$ test and correlation coefficient), and a path analysis using repeated-measure regression models. All analyses were conducted using SPSS version 16 (SPSS Inc., Chicago, IL, USA). 


\section{Results}

The demographic characteristics of the study subjects have been presented in Table 1 .

Table 1. Demographic Characteristics of Study Subjects

\begin{tabular}{l|c|c}
\hline Variable & & No. (\%) \\
\hline \multirow{2}{*}{ Gender } & Male & $143(37.3)$ \\
\cline { 2 - 3 } & Female & $241(62.7)$ \\
\hline \multirow{2}{*}{ Occupational status } & Employed & $136(35.2)$ \\
\cline { 2 - 3 } & Unemployed & $249(64.8)$ \\
\hline \multirow{3}{*}{ Academic grade } & Bachelor & $218(56.8)$ \\
\cline { 2 - 3 } & Master's degree & $98(25.5)$ \\
\cline { 2 - 3 } & PhD & $4(1.1)$ \\
\cline { 2 - 3 } & Professional doctoral degree & $54(14.1)$ \\
\hline
\end{tabular}

The mean $\pm S D$ of the studied variables and their aspects have been presented in Table 2 .

According to Table 2, students' total score on the attitude toward their university, and those on the academic, personal, and social aspects indicated that their attitudes toward the university were lower than the estimated average. Among the 3 aspects of students' attitudes toward the university, they exhibited highest and lowest mean scores on social and academic attitudes, respectively. Evaluation of the mean scores on academic procrastination indicated that procrastination resulting from disorganization and intentional procrastination had the highest and lowest mean values, respectively. With reference to academic burnout, the highest and lowest mean values were observed for the variables of academic failure and academic disinterest. To compare the students' attitudes toward their university between subjects from the selected universities, the independent t test was used. These results have been presented in Table 3.

As evident from Table 3, the comparison between students' attitude toward their university between subjects from the Mazandaran University of Medical Sciences and Islamic University, Sari Branch indicated no significant differences in terms of the social attitude toward the university; however, significant differences were observed regarding the personal and academic aspects. Additionally, significant differences were observed in students' total scores on attitudes toward the university among the subjects from the two universities. Since the mean score of students from Islamic Azad University was higher than that of students from the Mazandaran University of Medical Sciences, it can be concluded that the attitude of students in the former university was more positive as compared to that of the students from Mazandaran University.

A comparison of the level of academic procrastination between the students of the mentioned universities revealed no significant differences. With reference to the level of academic burnout, no significant differences were observed between the universities regarding the academic exhaustion and disinterest aspects; however, a significant difference was observed regarding academic failure. Further, the students of Islamic Azad University reported higher levels of academic burnout as compared to their counterparts from the Mazandaran University of Medical Sciences.

To compare the relationship of the attitudes of students toward the university with academic procrastination and its aspects, and with academic burnout and its aspects, the coefficient correlation was used (Table 4).

According to Table 4, there was a significant correlation between the students' attitudes toward the university and the level of academic procrastination and burnout $(\mathrm{r}=0.298$; P value $<0.05)$. The association between the students' attitudes toward the university and intentional academic procrastination was stronger than that observed for other aspects $(r=0.282)$. Additionally, a significant relationship was observed between the students' attitudes toward the university and academic burnout $(\mathrm{r}=0.491$; $\mathrm{P}$ value $<0.05)$. The relationship between the students' attitudes toward the university and the aspect of academic failure was stronger than that observed for the other aspects $(r=0.494)$.

To compare the relationship between the students' attitude toward the university and academic burnout, based on the mediating role of academic procrastination, a path analysis using the repeated-measure regression models was employed (Table 5).

According to Table 5, the variables of intentional procrastination, procrastination due to mental and physical fatigue, and personal and social attitudes had significant direct effects on academic burnout ( $P$ value $<0.05$ ). Additionally, personal and social attitudes had a significant direct effect on intentional procrastination and procrastination due to mental and physical fatigue (P value $<0.05)$. Further, academic, personal, and social attitudes also had a significant direct effect on procrastination due to disorganization (P value $<0.05$ ). Thus, the present findings revealed that personal and social variables of students' attitudes had direct and indirect effects on academic burnout, and these relationships were mediated by intentional procrastination and procrastination due to mental and physical fatigue (Figure 1). 
Table 2. The Mean \pm Standard Deviation of the Students' Attitude, Academic Procrastination, and Academic Failure

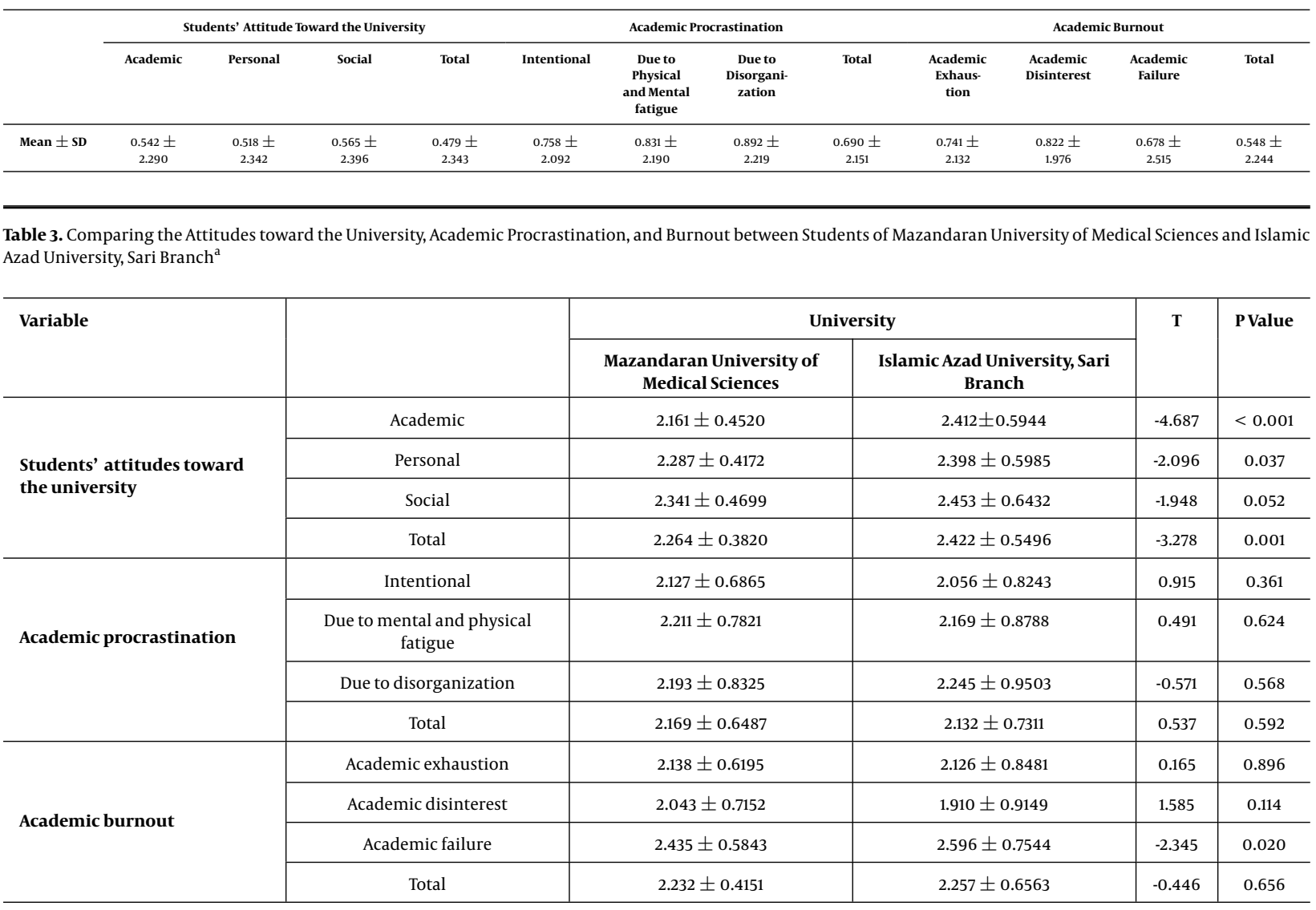

${ }^{\mathrm{a}}$ Values are expressed as mean $\pm \mathrm{SD}$.

Table 4. The Correlation Coefficient between Students' Attitudes toward the University and Academic Procrastination and Burnout

\begin{tabular}{|c|c|c|c|c|c|c|c|c|c|}
\hline \multirow{2}{*}{$\begin{array}{l}\text { Students' Attitudes } \\
\text { Toward University }\end{array}$} & & \multicolumn{4}{|c|}{ Academic Procrastination } & \multicolumn{4}{|c|}{ Academic Burnout } \\
\hline & & Intentional & $\begin{array}{l}\text { Due to Mental and } \\
\text { Physical Fatigue }\end{array}$ & $\begin{array}{c}\text { Due to } \\
\text { Disorganization }\end{array}$ & Total & $\begin{array}{c}\text { Academic } \\
\text { Exhaustion }\end{array}$ & $\begin{array}{c}\text { Academic } \\
\text { Disinterest }\end{array}$ & Academic Failure & Total \\
\hline & PValue & $<0.001$ & $<0.001$ & $<0.001$ & $<0.001$ & $<0.001$ & $<0.001$ & $<0.001$ & $<0.001$ \\
\hline
\end{tabular}

\section{Discussion and Conclusions}

The descriptive findings of the current study regarding students' academic, personal, and social attitudes toward their university revealed lower scores than the mean value. According to previous findings, in most cases, students' (especially freshmen's) expectations regarding their university did not coincide with what they experienced (25, 26). Students' academic and social experiences in the university made them conclude that their expectations were unreal and that they could not be met $(25,26)$. Although it seems that all students experience procrastina- tion at least for some period, it does not mean that most of them always deal with procrastination. On the other hand, the present study revealed that students experienced academic burnout and even some of them are involved in.

Results of the current study showed a significant relationship between the students' attitude toward their university and academic procrastination. This finding was in line with those reported by Sepehrian, who revealed a significant predictive effect of anxiety on academic procrastination (13). Additionally, the results of the study by Duru and Balkis showed that procrastination toward col- 
Table 5. Path-Coefficient Analysis of Variables with a Direct and Indirect Relationship with Academic Burnout

\begin{tabular}{|c|c|c|c|c|c|c|c|}
\hline Variables & & $\begin{array}{c}\text { Intentional } \\
\text { Procrastination }\end{array}$ & $\begin{array}{c}\text { Procrastination } \\
\text { Due to Mental } \\
\text { and Physical } \\
\text { Fatigue }\end{array}$ & $\begin{array}{c}\text { Procrastination } \\
\text { Due to } \\
\text { Disorganization }\end{array}$ & $\begin{array}{l}\text { Academic } \\
\text { Attitude }\end{array}$ & $\begin{array}{l}\text { Personal } \\
\text { Attitude }\end{array}$ & Social Attitude \\
\hline \multirow{2}{*}{$\begin{array}{l}\text { Intentional } \\
\text { procrastination }\end{array}$} & B coefficient & - & - & - & 0.027 & 0.201 & 0.275 \\
\hline & PValue & & & & 0.418 & 0.004 & $<0.001$ \\
\hline \multirow{2}{*}{$\begin{array}{l}\text { Procrastination } \\
\text { due to mental } \\
\text { and physical } \\
\text { fatigue }\end{array}$} & B coefficient & - & - & - & 1.250 & 0.233 & 0.223 \\
\hline & PValue & & & & 0.212 & 0.001 & 0.003 \\
\hline \multirow{2}{*}{$\begin{array}{l}\text { Procrastination } \\
\text { due to } \\
\text { disorganization }\end{array}$} & B coefficient & - & - & - & -0.177 & 0.161 & 0.311 \\
\hline & PValue & & & & -0.177 & 0.161 & 0.311 \\
\hline \multirow{2}{*}{$\begin{array}{l}\text { Academic } \\
\text { burnout }\end{array}$} & B coefficient & 0.317 & 0.157 & 0.58 & 0.015 & 0.221 & 0.196 \\
\hline & PValue & $<0.001$ & 0.001 & 0.214 & 0.777 & $<0.001$ & 0.001 \\
\hline
\end{tabular}

lege tasks was one of the most important factors involved in academic failure or lack of academic achievement (27).

Further, the present study revealed a significant relationship between the students' attitude toward their university and academic burnout. This finding was similar to that reported from a study by Mikaeili et al. (12), which showed a significant relationship of academic burnout and its subscales of academic exhaustion, disinterest, and failure with academic performance (12). Schaufeli et al. evaluated the relationship between academic engagement and academic burnout with academic performance, and reported a negative relationship between subscales of academic engagement and academic burnout, while they had positive relationship with academic performance (28). Academic failure among students refers to exhaustion pertaining to academic requirements, having a pessimistic attitude and disinterest toward academic tasks, and having a sense of lack of competence as a student (low efficacy) (10). Students' expectations of their university excessively affected their thoughts and performance when entering the university.

The results of the path analysis conducted in the present indicated the direct and indirect effects of the personal and social attitudes of students toward their university, and intentional procrastination and procrastination due to mental and physical exhaustion, on their academic burnout. Findings of the current study also showed that intentional procrastination and procrastination due to mental and physical exhaustion affected the academic burnout only directly. However, the personal attitude of students had direct and indirect effects on their academic burnout, and this relationship was mediated by intentional procrastination and procrastination due to mental and physical exhaustion. The social attitude of students also had direct and indirect effects on their academic burnout, which was mediated by intentional procrastination and procrastination due to mental and physical exhaustion.

Based on the findings of the current study, it seems that students' attitude toward the university affected their academic burnout level, which was medicated by academic procrastination. Students' perceptions and beliefs about the university environment significantly affected their efficacy and satisfaction. These negative factors may lead even a competent student to drop out of the university, or, in milder cases, may lead to the development of academic procrastination owing to the assumption that he/she cannot meet the expectations and/or that the expectations are illogical. Procrastination results in loss of opportunities, time, income, demoralization, stress increase, anxiety, fear, and lower motivation in the students. When the student experiences such mental pressure and stress, he/she develops academic exhaustion and pessimism, which may result in academic burnout.

Academic burnout is in contrast to academic interaction, as the latter is related to higher degrees of mental capability and flexibility during studying, feeling of important and excited with studies, being inspired by studying, being able to concentrate adequately, being happy, and being attracted by studying (28). Burnout is a problematic phenomenon that results in poor performance (29). In other words, despite pleasant experience at the university, academic contents such as tests, lectures, presentations, etc., may result in academic burnout in some students (6). On the other hand, students' burnout may cause more absence, less motivation to engage in academic tasks, higher rates of university withdrawal, etc. (10). The university authorities should therefore implement measures to reduce stress in students through appropriate curriculum, goal setting, task assigning, availability of teachers for adequate guidance and support, verbal persuasion, and 
assigning tasks that are associated with personal success. Such conditions remarkably affect the students' attitude toward the academic environment.

Students' academic burnout and procrastination can affect their scientific destiny and may also have a negative influence on their mental and physical health. These complications, in turn, would increase their academic and professional failures. Hence, it is recommended that university authorities provide providing suitable conditions for students' growth and development, fair and unbiased treatment by the university professors and authorities, giving enough time to perform academic tasks, appropriate evaluation, and social support to alleviate academic burnout and procrastination in students.

\section{Supplementary Material}

Supplementary material(s) is available here.

\section{Acknowledgments}

The authors hereby wish to thank the students who participated in the current study, for their kind cooperation.

\section{References}

1. Farahbakhsh S, Gholamrezaei S, Nikpay I. The survey of students'mental health in relation to academic factors. J Fundament Ment Health. 2007;9:33-4.

2. Shih SS. An investigation into academic burnout among Taiwanese adolescents from the self-determination theory perspective. Soc Psychol Educ. 2015;18(1):201-19. doi: 10.1007/s11218-013-9214-x.

3. Gan Y, Shang J, Zhang Y. Coping Flexibility and Locus of Control as Predictors of Burnout among Chinese College Students. Soc Behav Pers int j. 2007;35(8):1087-98. doi: 10.2224/sbp.2007.35.8.1087.

4. Zhang Y, Gan Y, Cham H. Perfectionism, academic burnout and engagement among Chinese college students: A structural equation modeling analysis. Pers Individ Differ. 2007;43(6):1529-40. doi: 10.1016/j.paid.2007.04.010.

5. Magnusson AE, Nias DK, White PD. Is perfectionism associated with fatigue? J Psychosom Res. 1996;41(4):377-83. [PubMed: 8971668].

6. Behroozi N, Shahni Yelaq M, Pourseyed SM. Relationship between perfectionism, perceived stress and social support with academic burnout. Strateg Culture. 2013;5(20):83-102.

7. Rostamogli Z, Khoshnoodnia CB. Comparing academic conscience and academic burnout in students with and without learning disabilities. J Learn Disabil. 2013;3(6):18-37.

8. Duran A, Extremera N, Rey L, Fernandez-Berrocal P, Montalban FM. Predicting academic burnout and engagement in educational settings: assessing the incremental validity of perceived emotional intelligence beyond perceived stress and general self-efficacy. Psicothema. 2006;18 Suppl:158-64. [PubMed: 17295974].
9. Heidari S, Maktabi GHH. The comparison of cultural intelligence, angeles loneliness, academic burnout and mental health in master of art ahwaz female native and non-native students. Woman Culture. 2011;3(9):45-57.

10. Hayati D, Ogbahi A, Hoseini AA, Azizi AM. Investigating the relationships between quality of learning experience's components and self-efficacy on academic burnout among students of Allamme Tabatabaei University of Tehran. Educ Dev Jundishapur. 2012;3(4):18-29.

11. Naami AAZ. Relationship between quality of Learning Experiences and Academic Burnout in graduate students of Shahid Chamran university. Psychol Stud. 2009;5(3):117-34.

12. Arefnia S, Sarandi P, Yousefi R. The comparison of early maladaptive schemas in secondary school students with and without school anxiety. J School Psychol. 2013;1(4):124-30.

13. Sepehrian F. Academic Procrastination and its predictive factors. JPsychol Stud. 2012;7(4):9-26.

14. Golestani Bakht T, Shokri M. Relationship between academic procrastination with meta cognitive beliefs. Soc Cogn. 2013;2(3):89-100.

15. Steel P. The nature of procrastination: a meta-analytic and theoretical review of quintessential self-regulatory failure. Psychol Bull. 2007;133(1):65-94. doi: 10.1037/0033-2909.133.1.65. [PubMed: 17201571].

16. Shokri M. Relationship between procrastination with anxiety and metacognition beliefs of high school students of Amol city. Mazandaran: Islamic Azad University Sari Branch; 2014.

17. Karami D. Prevalence of procrastination among university students and its relationship with anxiety and depression. Appl Psychology. 2009;4(13):25-34.

18. O'Brien WK. Applying the transtheoretical model to academic procrastination. ProQuest Information \& Learning; 2002.

19. Day V, Mensink D, O'Sullivan M. Patterns of academic procrastination. J College Read Learn. 2000;30(2):120-34.

20. Tamadoni M, Hatami M, Hashemi R. General self efficacy, academic procrastination and academic achievement in university students. Educ Psychol. 2010;6(17):65-86.

21. Weinstein CE, Palmer DR. LASSI-HS user's manual. H \& H Pub.; 1990.

22. Nolen-Hoeksema S, Loftus G, Wagenaar W. Atkinson \& Hilgard's introduction to psychology. Massachusetts: Cengage Learning; 2009.

23. Sevari K. Construction and standardization of Academic procrastination test. Train Measure. 2011;2(5):97-110.

24. Breso E, Salanova M, Schaufeli WB. In Search of the "Third Dimension" of Burnout: Efficacy or Inefficacy? Appl Psychol. 2007;56(3):460-78. doi: 10.1111/j.1464-0597.2007.00290.x.

25. Smith JS, Wertlieb EC. Do First-Year College Students' Expectations Align with their First-Year Experiences? NASPA J. 2005;42(2) doi: 10.2202/0027-6014.1470.

26. Holmstrom LL, Karp DA, Gray PS. Why Laundry, Not Hegel? Social Class, Transition to College, and Pathways to Adulthood. Symbol Interact. 2002;25(4):437-62. doi: 10.1525/si.2002.25.4.437.

27. Balkıs M, Duru E. Prevalence of academic procrastination behavior among preservice teachers, and its relationships with demographics and individual preferences. J Theory Pract Educ. 2009;5(1):18-32.

28. Schaufeli WB, Martínez IM, Pinto AM, Salanova M, Bakker AB. Burnout and Engagement in University Students. J Cross Cultur Psychol. 2016;33(5):464-81. doi:10.1177/0022022102033005003.

29. Steel P, Brothen T, Wambach C. Procrastination and personality, performance, and mood. Pers Individ Differ. 2001;30(1):95-106. doi: 10.1016/s0191-8869(00)00013-1. 